\title{
EL CONCEPTO SEGUNDA INDEPENDENCIA EN LA HISTORIA DE LAS IDEAS EN AMÉRICA LATINA: UNA MIRADA DESDE EL BICENTENARIO'
}

\author{
THE CONCEPT OF SECOND INDEPENDENCE IN THE HISTORY \\ OF IDEAS IN LATIN AMERICA: A BICENTENARY PERSPECTIVE
}

\section{JAVIER PINEDO ${ }^{2}$}

\section{RESUMEN}

El artículo, a través de cinco reflexiones, analiza la historia, aplicación y significado del concepto Segunda Independencia, desde su inicio en los pensadores románticos del siglo XIX (Esteban Echeverría, José Victorino Lastarria, Francisco Bilbao); más tarde con José Martí que lo consolida definitivamente; deteniéndose en el Chile de los años 60, y lo establecido por Salvador Allende. Por último, se analiza la situación actual y cuál debería ser su vigencia en el futuro, de cara al Bicentenario.

Palabras clave: Pensamiento en América Latina, Segunda Independencia, Bicentenario.

\section{ABSTRACT}

The article, through five different considerations of the topic, analyzes the history, application and significance of the idea of a Second Independence beginning at its source with the romantic thinkers of the $19^{\text {th }}$ Century (Esteban Echeverría, José Victorino Lastarria, Francisco Bilbao); later gaining strength and clarity with José Martí; coming to rest in the Chile of the 60s and the point of view of Salvador Allende. Finally, the current situation and what should be its future validity with a view to the Bicentennial is analyzed.

Keywords: Thought in Latin America, Second Independence, Bicentennial.

Recibido: 18.07.2010. Aprobado: 10.10.2010.

${ }^{1}$ Este trabajo fue escrito en el marco de la investigación:"Ensayo literario, ciencias sociales, pensamiento político, sensibilidades, y su relación con las redes intelectuales, en los (largos) años 60 en Chile: 1958-1973", financiado por Fondecyt Chile, con el número 1030097.

${ }^{2}$ Dr. en Literatura, profesor-investigador, Instituto de Estudios Humanísticos de la Universidad de Talca.Talca, Chile.E-mail: jpinedo@utalca.cl

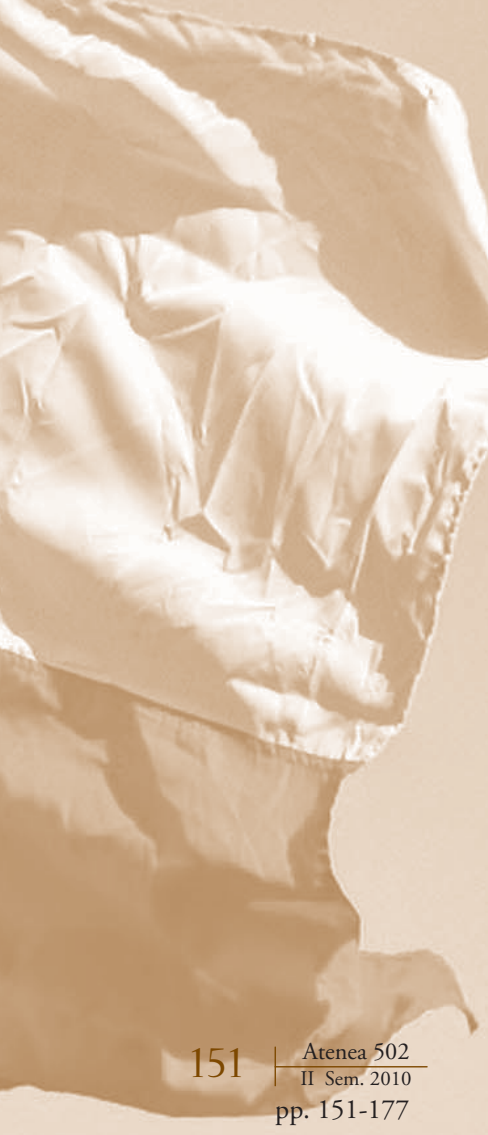




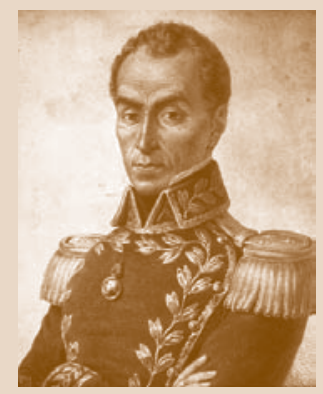

S. Bolívar

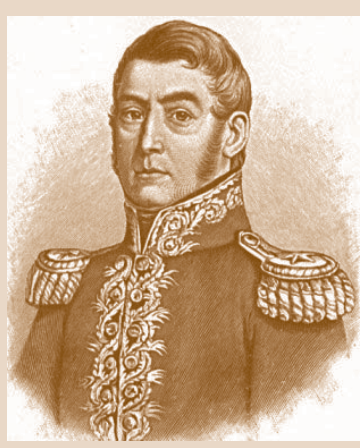

J. de San Martín

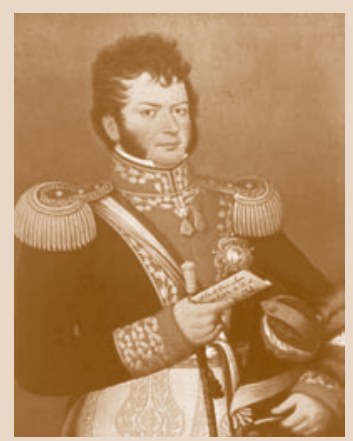

B. O’Higgins
$\mathrm{E}$ L CONCEPTO “independencia" tiene su origen en la Europa del siglo XVIII, y es uno de los pilares de la modernidad ilustrada, que se manifiesta en categorías como emancipación, libertad, independencia, revolución, todas ellas para significar lo que Kant, en su famoso, ¿Qué es la ilustración?, al definir la modernidad como "la salida del hombre de su minoría de edad de la que es culpable", señala a esta minoría de edad como "la incapacidad de servirse de la propia razón sin requerir la ayuda de otro"; es decir, la ilustración consistía en la liberación de estructuras sociales que nos encadenan al no ser comprendidas.

Bajo estos conceptos se realizaron la independencia de los EE.UU. (1776) y la gran revolución francesa (1789), que son los dos acontecimientos políticos y sociales que configuran, políticamente, la modernidad ilustrada.

En el caso de la independencia de América Latina, que constituye el tercero de los acontecimientos políticos modernos, Bolívar, y los demás líderes, manifiestan, tempranamente, una gran cercanía al programa ilustrado en el uso de conceptos como: libertad, democracia, educación, laicismo, progreso; los que se alcanzarían al momento de lograr la "libertad de la patria", antes, tal vez, que la de los individuos.

Las palabras libertad, emancipación, independencia, anuncian el proceso que permitiría poner fin a la presencia de España en América, con una ruptura con el orden colonial, tanto en lo político (la dependencia de la corona), como en lo social y cultural (terminar con una religiosidad intransigente), y del cual no recuperan nada, por lo que la independencia es una etapa histórica que comienza desde cero, en un presente que se transformaba en un estado adánico y de orfandad ${ }^{3}$.

A pesar de los buenos deseos y las amplias esperanzas, la independencia nos ofrece la sensación de un temprano fracaso. En lo personal, sus líderes, contrariamente a los estadounidenses, concluyen mal sus días percibiendo que no han logrado lo que intentaban alcanzar: Bolívar, San Martín, O'Higgins mueren en el exilio, e incluso, al primero, Venezuela le retira la ciudadanía. José Antonio Sucre es asesinado en una emboscada; Miranda muere preso en Cádiz, y la pobreza y el abandono rodearon el final de todos.

En lo institucional, la economía no produjo el éxito esperado y la deuda

${ }^{3}$ Ver, José Luis Romero y Alberto Romero, El pensamiento de la emancipación (1790-1825) (1977). En este texto se transcriben los discursos de una importante cantidad de pensadores emancipadores, aunque no se define el concepto emancipación, su origen ni uso. 
externa se transforma en un mal endémico, en muchos casos hasta el presente, a lo que se suman los casos de anarquía social y sanguinarias dictaduras. Durante la post independencia, la realidad americana se vuelve más compleja de gobernar, y es en este contexto que surgen frases como "He arado en el mar", o angustiadas preguntas como el "Quiénes somos", que manifiestan el desconsuelo de los libertadores.

Frente a esta sensación de fracaso surgirá la necesidad de una Segunda Independencia, es decir, de una nueva oportunidad que permita concluir favorablemente la frustrada etapa anterior.

Desde este punto de vista resulta esclarecedora la distinción que establece Hanna Arendt entre "liberación" y "libertad": la primera puede ser una condición de la libertad, pero no conduce necesariamente a ella (Arendt 1988); a partir de las diferencias entre la independencia de los EE.UU., que busca la libertad individual, y la revolución francesa, que intenta la emancipación de un poder absoluto; mientras que los procesos independentistas de Hispanoamérica, guerras de liberación en contra del poder colonial español, que no siempre dieron origen a gobiernos que fomentaran la libertad individual, sino a un poder político que asegure el control social.

Arendt utiliza muchas distinciones que nos llevaría muy lejos analizar: hombres libres, esclavos; hombres de las revoluciones; revolucionarios profesionales; y otras. Y aunque en estas distinciones no se considera la situación de la Independencia latinoamericana, se establecen criterios que nos permiten revisarla de una nueva manera, como, por ejemplo, que la acción de los líderes latinoamericanos está marcada por la guerra, más que por la construcción de espacios de libertad. Más cercanos a Robespierre, y su afán de construir una "República" y una "Constitución”, cuya preservación será lo importante. "Libertad y poder se han separado, con lo cual ha comenzado a tener sentido la funesta ecuación de poder y violencia, de política y gobierno y de gobierno y mal necesario" (Arendt 1988: 138).

Incluso, en términos contemporáneos, para Hanna Arendt, la superación de la pobreza es distinta de los principios que habían inspirado la fundación de la libertad:

El sueño americano, como lo entendieron los siglos XIX y XX bajo el impacto de la inmigración masiva, no fue el sueño de la Revolución americana -la fundación de la libertad- ni el de la Revolución francesa: la liberación del hombre; se trató desgraciadamente del sueño de una "tierra prometida" donde abundasen la leche y la miel. El hecho de que el progreso de la tecnología moderna fuese capaz de realizar tan pronto ese

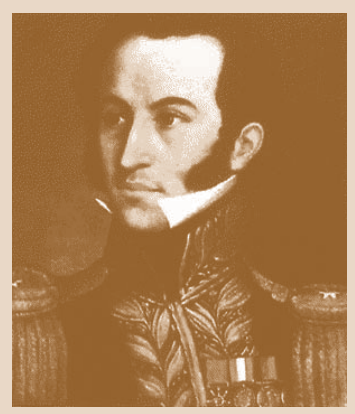

A. Sucre

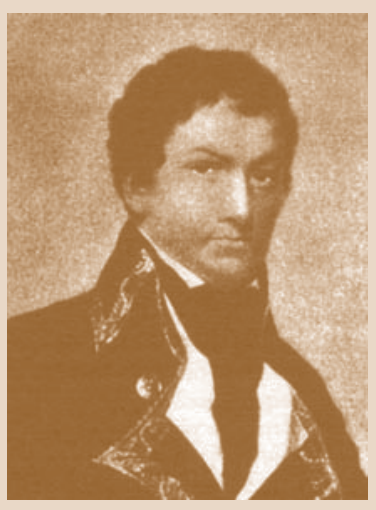

F. A. de Miranda 
sueño más allá de toda esperanza, tuvo el efecto de confirmar a los soñadores que habían venido realmente a vivir en el mejor de los mundos posibles ${ }^{4}$.

Siguiendo a Arendt, podemos decir que tanto los revolucionarios estadounidenses como franceses, son civiles de obra y pensamiento, políticos y constitucionalistas; mientras que los latinoamericanos están más cerca del mundo militar, y es la fase de la guerra la que importa, después de la cual se enfrentan a un espacio difícil de llenar, pues la emancipación de España ya ha sido conseguida; por lo que, en muchos casos, permaneció la inercia de la guerra, contra enemigos que se iban modificando a través del tiempo.

Lo anterior hizo que el proyecto de independencia en América Latina haya estado marcado por ciertos rasgos específicos: centralismo, autoritarismo, y una débil burguesía, que no produjo ni industrialización, ni una política igualitaria: un proceso social diferente al estadounidense y francés.

Si es cierto, que con la independencia se inicia en la mayoría de los países latinoamericanos la libertad religiosa, educacional y de prensa, se trata de una libertad llena de ambigüedades. Jorge Larraín (2005) señala tres aspectos básicos del periodo post independencia:

1. Un carácter imitativo que copia constituciones políticas de Europa o Norteamérica. Desde 1811 hasta 1830, por ejemplo, 17 países de América Latina promulgan constituciones inspiradas en la de Filadelfia.

2. Este carácter imitativo produjo un orden jurídico efímero y de poco éxito, en el que muy pocas constituciones logran sobrevivir (la chilena de 1823 duró sólo un año), dejando la puerta abierta a dictaduras que confirman las dudas que los libertadores tenían sobre el éxito de la democracia en América Latina.

3. En este contexto político, la participación popular fue restringida: el derecho a voto estuvo limitado y los fraudes electorales se reiteraron, lo que produjo una modernización de carácter oligárquico.

Desde esta sensación de fracaso histórico surge una nueva generación de pensadores (románticos, liberales, civilizadores), que postulan la necesidad de una nueva independencia, más cultural que política, que permitiera re-

\footnotetext{
${ }^{4}$ Hay que tener en cuenta, para comprender cabalmente la cita, la opinión de Hanna Arendt sobre pobreza y política: "El deseo oculto de los pobres no es 'a cada uno según sus necesidades', sino 'a cada uno según sus deseos'. Aunque es cierto que la libertad sólo puede llegar a quienes tienen cubiertas sus necesidades, también es cierto que nunca la lograrán aquellos que están resueltos a vivir de acuerdo con sus deseos" (Arendt 1988: 140).
} 
solver los conflictos y dudas heredadas de la primera independencia. Dudas sobre el tipo de gobierno más adecuado para América Latina ${ }^{5}$, o todavía, sobre la propia realidad humana del continente ${ }^{6}$.

Esta generación tradujo en el concepto Emancipación mental, un programa que permitiera resolver los conflictos pendientes, y una temprana decepción en América Latina, a menos de 30 años de la independencia.

Ante tal panorama, la necesidad de una nueva independencia integral, que abarcara tanto aspectos políticos como culturales y jurídicos, se imponía en las conciencias de los nuevos pensadores.

\section{SEGUNDA REFLEXIÓN: DE LA INDEPENDENCIA POLÍTICA A LA CULTURAL}

Para los liberales, la Segunda Independencia corresponde a una fase posterior a la liberación del dominio español, y que se alcanzaba con la creación de una cultura cívica autónoma, que destacara al Nuevo Mundo como una identidad reconocible para sí mismo, y para el centro europeo-norteamericano. La independencia no es vista como un proceso concluido, sino por terminar.

Los liberales denominaron "emancipación mental" a este segundo intento por alcanzar el proyecto moderno ${ }^{7}$; pero, se trata también de un concepto utilizado para marcar la distancia de América Latina independiente, en relación con la modernidad (política y económica) alcanzada por los Estados Unidos y algunos países europeos paradigmáticos (Francia e Inglaterra), a los que los pensadores latinoamericanos tomaron como modelo y vara para medir su propio estado de desarrollo y su lugar entre la civilización que surgió después de la revolución francesa y el capitalismo industrial.

Es lo que Esteban Echeverría, en el Dogma socialista", denomina la “Eman-

\footnotetext{
${ }^{5}$ Ver, por ejemplo, el "Discurso de Angostura” de Simón Rodríguez, o las “Cartas” de Diego Portales, en los que se pasa revista a los tipos de gobierno existentes. En general todos están de acuerdo en la república, pero siempre con restricciones, nacidas, según ellos, de la propia realidad americana.

${ }^{6}$ Simón Bolívar en “Carta de Jamaica”, se pregunta: “¿Qué somos?, ¿Indios?, ¿Españoles?, ¿Americanos?, ¿Europeos?” (Bolívar 1979). Pregunta que permanece pendiente a lo largo del siglo XIX y que Sarmiento al cerrar el siglo, reitera en un “¿Qué somos?”, expuesto en Conflictos y armonías de las razas en América (Sarmiento 1883).

${ }^{7}$ Por ejemplo, José Luis Mora (1986), siguiendo de cerca a Kant, habla de "la mayoría de edad mental".

${ }^{8}$ Dogma Socialista de la Asociación de Mayo, 1837, en Echeverría (1873: 117-203).
}

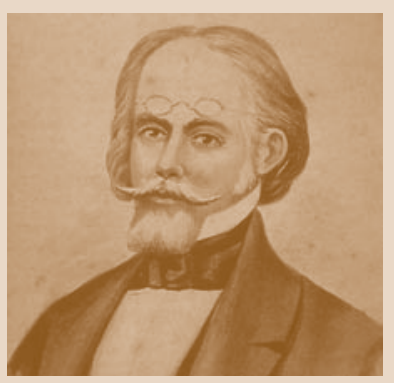

S. Rodríguez

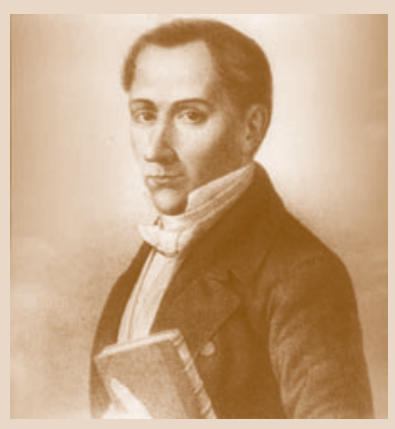

D. Portales 
democráticas y al sufragio universal, que en aquellas circunstancias, habrían permitido el triunfo de un pueblo, a sus ojos violento, insensato y ajeno a los códigos burgueses que habían permitido la independencia de 1810, y que ese mismo pueblo no había logrado asimilar. La democracia, para Echeverría, tiene un sentido racional y no popular: Y, en Dogma socialista, escribe: "La democracia, pues, no el despotismo absoluto de las masas, ni de las mayorías, es el régimen de la razón”. Y la razón-para él- está encarnada en los intelectuales y los sujetos de mayor lucidez en la sociedad, de modo similar a como los concebirá, más tarde, Ortega y Gasset.

El drama de Echeverría y su generación se plantea en las siguientes preguntas: ¿Cómo civilizar (modernizar) a un pueblo afectado por el atraso político y carente de las normas básicas de convivencia burguesa? ¿Cómo gobernar democráticamente un país que no está preparado para la democracia? Las respuestas que entrega en sus obras literarias plantean la impotencia del hombre civilizado frente al bárbaro, y no hay en Echeverría el optimismo de alcanzar con facilidad, ni la Segunda Independencia, ni la Emancipación mental: “... esta sociedad, pues, en que la cultura del espíritu es inútil e imposible". Este objetivo (alcanzar un "pacto social" que permita la incorporación de América Latina al proyecto moderno) permanecerá como una tarea pendiente para el futuro. Siempre para el futuro. Pues, en América Latina, el "espíritu nuevo no ha aniquilado completamente al espíritu de las tinieblas"10.

No se trata, ahora, de la emancipación de un poder extranjero, sino de la liberación de la propia realidad social. Así, alcanzar la Emancipación mental (europeizar la realidad) se constituirá en la tarea fundamental del liberalismo latinoamericano del siglo XIX, pues mientras ésta no sea lograda, los países recién independizados estarán obligados a repetir la dictadura propia y la del yugo extranjero (Ossandón 1984).

A partir de esta idea, la Emancipación mental (la Segunda Independencia) adoptará diversas variantes según la ideología de cada pensador: para Echeverría el concepto adopta la necesidad de europeizar las costumbres para alcanzar los valores republicanos.

Domingo F. Sarmiento, por su lado, propondrá un programa más radical para lograr un "pacto social", basado en eliminar la distancia racial-educacional, que diferenciaba a la América Latina de la sajona, estableciendo

\footnotetext{
${ }^{10}$ Entre las obras literarias de Echeverría, los dos ejemplos más dramáticos y pesimistas son $\mathrm{El}$ matadero (1838) y La cautiva (1837). La fiera visión del bajo pueblo de la periferia de Buenos Aires, mostrada en la primera de estas obras, es reemplazada por la sanguinaria imagen del indígena en la segunda. En ambas, el hombre burgués, blanco y moderno, sucumbe.
} 
los Estados Unidos?”, responde con la inmigración: “... traigamos pedazos vivos de ellos en las costumbres de sus habitantes y radiquémoslos aquí". Su respuesta es conocida: para alcanzar la civilización deben traer nuevas mentalidades (modernas) que señalen el camino, tanto en educación como en política y economía.

Se propondrá así la deslatinización de Latinoamérica. Los mexicanos, para resistir al invasor, le entregan su esencia confundiéndose con él; los americanos del sur, queriendo cortar los últimos lazos de la colonización hispana, aceptan el tutelaje mental, cultural, político y económico de la Europa moderna y su expresión en América del norte. Ser como los norteamericanos para no ser dominados por ellos o ser, simplemente, los yankees del sur para poder ser así parte del mundo que éstos, con su acción, han creado ${ }^{11}$.

En el caso chileno, los pensadores más representativos para comprender el concepto de Segunda Independencia, son José Victorino Lastarria y Francisco Bilbao (1844), y en ambos se manifiesta la misma preocupación por pasar de una cultura de las armas (Primera Independencia) a una de las letras (Segunda Independencia), para alcanzar la emancipación (espiritual, literaria, cultural) y construir una literatura latinoamericana propia, que permita valorizar a América Latina.

Es interesante destacar que ninguno de los dos utiliza de manera radical las categorías de "civilización y barbarie", tan extendidas entre los liberales, y Lastarria, aunque entrega su voto a favor de lo extranjero, presenta una variante proindigenista de la emancipación, al considerar la independencia de Chile como una consecuencia de las luchas mapuches.

En la Memoria histórica que presentó a la Universidad de Chile en 1844, José Victorino Lastarria sostuvo que el proceso de independencia nacional había respondido a una voluntad de emancipación nacida con la resistencia indígena al colonialismo hispano (...) Bajo esta perspectiva, el despotismo no sólo era un rasgo propio del colonialismo hispano sino que su persistencia sobre las sociedades latinoamericanas hacía de su desmontaje el principal desafío postcolonial. Así, Lastarria hurgó en la colonia el origen de una voluntad de emancipación que, nacida con la resistencia indígena, delineaba el horizonte político de una nación en

\footnotetext{
${ }^{11}$ Cristián Candia Baeza, "Filosofía, identidad y pensamiento político en Latinoamérica", Polis. Revista Académica Universidad Bolivariana, $\mathrm{N}^{\circ} 18$ Santiago de Chile, http://www.revistapolis.cl/ 18/filo.htm [Consulta: 14.05.2010].
}

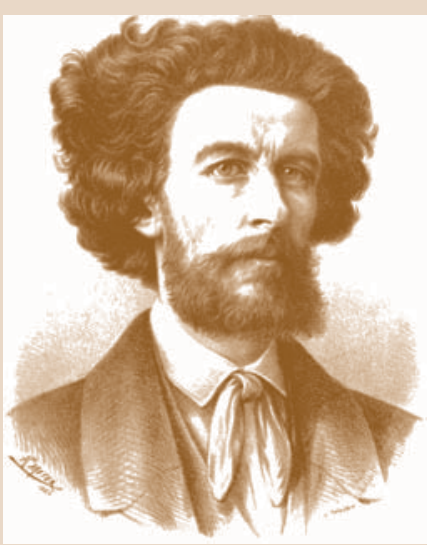

F. Bilbao 


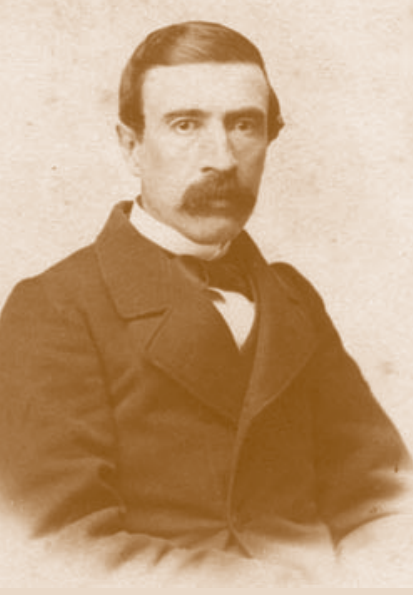

J. V. Lastarria construcción. El vínculo entre emancipación y soberanía ordenó la mirada a la historiografía y filosofía de la historia planteada por Lastarria en su presentación ante la Universidad de Chile (...) Allí, Lastarria, afirmó que, a pesar de haber sido sepultados por un orden erigido sobre los escombros de su resistencia, los araucanos legaron una voluntad de redención política que nutría el discurso de emancipación nacional. Si bien esta visión fue rechazada por Andrés Bello y Domingo Faustino Sarmiento, todos coincidían en la incompatibilidad existente entre proyecto nacional y población indígena (Kaempfer 2006: 9-24).

La exposición de Lastarria nos permite observar una variante de cómo alcanzar la emancipación, confirmando de modo opuesto a los antiindigenistas, que "el pueblo era el único agente capaz de desmontar el colonialismo sino que identificó ese pueblo con el mestizo y lo postuló como el agente soberano de un relato nacional de emancipación" (Kaempfer 2006) ${ }^{12}$.

Esta identificación con una sociedad consolidada de manera socialmente más amplia, le permite a Lastarria señalar en el "Discurso inaugural de la Sociedad Literaria” (1842) la necesidad de “... manifestar al mundo que ya nuestro Chile empieza a pensar en lo que es y en lo que será”. Y luego: "No hay sobre la tierra pueblos que tengan como los americanos una necesidad más imperiosa de ser originales en su literatura, porque todas sus modificaciones le son peculiares y nada tienen en común con las que constituyen la originalidad del Viejo mundo”. Sólo así se podría alcanzar el proyecto final: la Segunda Independencia espiritual: “... la emancipación del espíritu es el gran objetivo de la revolución hispano-americana” (Lastarria, La América (1844), en Zea (comp.) 1993: II, 493-511).

El rescate de la peculiaridad de América Latina y su representación en los códigos literarios rompía la distancia con la cultura europea, aun cuando hubiera que imitar esos códigos formales, ocultando en el proceso justamente aquellos contenidos que se quería mostrar como originales. Es una de las paradojas de los pueblos periféricos, en su camino hacia la modernidad.

En el caso de Francisco Bilbao, la Segunda Independencia se relaciona con el fin del hispanismo que se mantenía en las costumbres sociales, como un modo de alcanzar la necesaria Emancipación mental. Pero, y de manera opuesta a Sarmiento y Alberdi, para quienes la solución era merecer la civilización (la razón) por la traída de extranjeros, para Bilbao, más cercano a Lastarria, se trataba de incorporar el mundo popular, dando un paso ade-

\footnotetext{
${ }^{12}$ José Victorino Lastarria presenta su "Memoria” en la Universidad, bajo el título de "Investigación sobre la influencia de la Conquista y del sistema colonial de los españoles en Chile”, en 1843.
} 
lante en la política liberal, hacia una visión comunitaria y social, que algunos han considerado como socialista (ver Jalif 2003; Loyola et al. 2005: 245264).

Bilbao comprende la Emancipación mental como la despañolización de América y el fin del catolicismo tradicional y su reemplazo por uno menos ortodoxo, pero también la incorporación de las clases sociales marginales y la desconfianza en las soluciones europeas o norteamericanas (Bilbao, en Zea (comp.) 1993: I, 53-66).

Para ambos chilenos, como para el resto, la independencia política no había sido suficiente, y ahora era necesario cambiar las costumbres y modelos de vida del pasado y la insatisfacción frente al presente, del que se culpa a un hispanismo todavía presente. Los 300 años de época colonial representaban una cultura (irracional y autoritaria) a la que se debía poner fin.

Al concluir el siglo, Gabino Barreda retoma en "Oración cívica", leída en México el 16 de septiembre de 1867, el concepto de "emancipación mental”:

... la emancipación mental, caracterizada por la gradual decadencia de las doctrinas antiguas, y su progresiva substitución por las modernas; (...) Emancipación científica, emancipación religiosa, emancipación política: he aquí el triple venero de ese poderoso torrente que ha ido creciendo de día en día, y aumentando su fuerza a medida que iba tropezando con las resistencias que se le oponían... (Barreda 1867).

Como los demás, Barreda, a través de la Emancipación mental, buscaba la libertad para México; es decir, alcanzar todo aquello que permanecía pendiente desde la inacabada primera independencia.

Las ideas anteriores fueron paradigmáticamente expuestas por José Martí, cuando en Nuestra América escribe de una manera que consolida para siempre la expresión, Segunda Independencia, como propia del pensamiento latinoamericano crítico y utópico: "De la tiranía de España supo salvarse la América española; y ahora, después de ver con ojos judiciales los antecedentes, causas y factores del convite, urge decir, porque es la verdad, que ha llegado para la América española la hora de declarar su segunda independencia" (Martí 1977a: 48).

El concepto Segunda Independencia, como un blindaje ante una "modernidad impuesta", y el levantamiento de un proyecto de "modernidad rechazada", se transforma en una expresión con gran fuerza literaria, y a la que se recurre muchas veces para sortear crisis económicas y políticas reales (Volek 2007).

En resumen, a pesar de los encantos literarios de Echeverría, de los es-
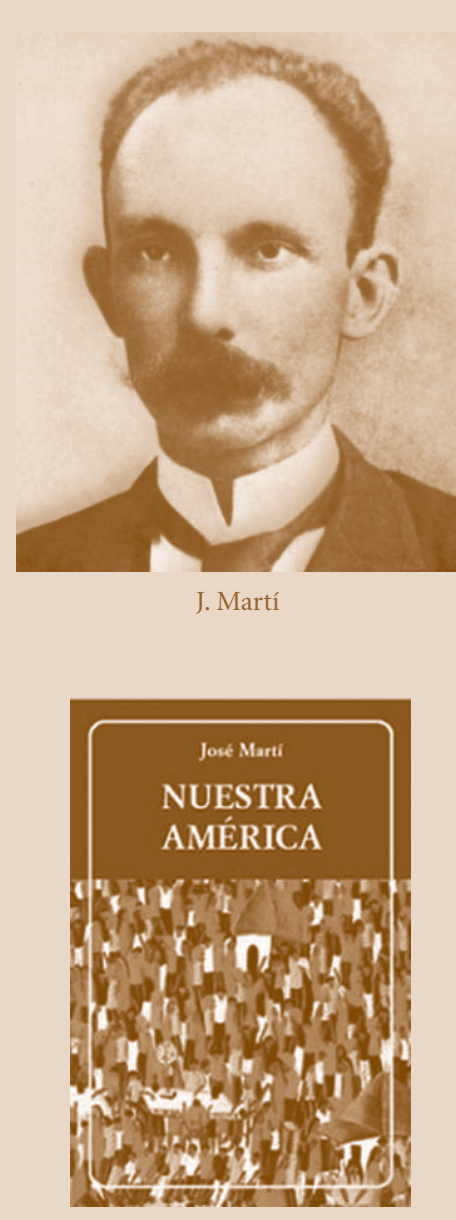
fuerzos educacionales (correctos) y erróneos (racismo) de Sarmiento y Alberdi, y del ahínco cultural de Lastarria, y otros liberales, y aun de los esfuerzos de Martí, durante el siglo XIX no se logró nada parecido a una Segunda Independencia, aunque sí cierta hegeliana toma de conciencia de las singularidades culturales y políticas de América Latina, que sin embargo no se tradujeron en proyectos políticos que permitieran la libertad y el desarrollo. Esta toma de conciencia permitió comprender la situación de sometimiento en que permanecía América Latina, como de culpabilizaciones ajenas de las desgracias propias: lo hispano, lo indígena, Francia, Inglaterra, EE.UU.; un esquema en el que sólo se salvaba una especie de proyecto mental ideal, que servía de modelo y refugio.

Ser nosotros mismos (independientes) significaba no ser españoles, pero sí europeos (Subercaseaux 1981). Por cierto, un "nosotros", que visto desde hoy, aparece restringido a un sujeto criollo con un proyecto de modernizar el país para sí mismo, y por su no aceptación del mundo indígena (Roig 1981).

Lo mental puede tener dos lecturas: la primera, más evidente, que se asocia con cambiar el modo de pensar tradicional, colonial y tomista, para asumir la manera moderna de ejercer el intelecto por medio de la razón, la ciencia, la filosofía. Para poner en práctica esta nueva manera de reflexionar y masificarla entre la población, sus partidarios acuden a la educación, en sentido amplio, a través de la escuela, el periodismo y la literatura, o ciertas acciones de participación política republicana. Esta perspectiva tiene una dirección hacia el futuro y confía en él. Así fue leída la Emancipación mental, por clásicos del pensamiento como Leopoldo Zea, que ven en ella la emancipación definitiva, al elevar la conciencia latinoamericana a un nivel superior.

La segunda interpretación apunta al subjetivismo de un ser social aislado, que desde los esquemas de su propia construcción mental niega la realidad por ser opuesta a sus creencias, por lo que concluye encerrándose en sí mismo. Esta otra perspectiva es más escéptica (más romántica) y no parece ir hacia ningún futuro, pues a este sujeto le parece imposible modificar un mundo social por demasiado atrasado. Aquí se podría ser libre mentalmente, pero no materialmente.

Es posible que ambas interpretaciones hayan estado presentes en un mismo autor, sobre todo en los argentinos, pues los chilenos fueron menos antiindigenistas. Pero, también es cierto, que en el caso de Echeverría se da casi exclusivamente la segunda perspectiva: mirar el mundo desde un estado mental particular, sin relación con el cambio del mundo real. Es sobre todo esta línea la que dará origen al "utopismo latinoamericano". 
En ambas, la pregunta por el "ser latinoamericano" es fundamental, pues responderla (más negativa que positivamente) es también una forma de Emancipación mental, al tomar conciencia de la identidad que se es.

Nos queda más claro, así, la existencia de dos tendencias en la concepción del concepto Emancipación mental y su equivalente Segunda Independencia: una de carácter más "mental", en sentido hegeliano, y en la que importan más las ideas, los principios y los sistemas de pensamiento que la realidad. Y otra, más práctica y más preocupada de la política y la educación, con propuestas de traer inmigrantes e imitar modelos extranjeros, formada por los modernizadores: Sarmiento, Alberdi, Lastarria.

Más tarde, durante el siglo XX, el intento de alcanzar una Segunda Independencia ha estado presente en los pensadores y los políticos latinoamericanos, como un recurso útil para expresar los deseos de un futuro mejor, y para denunciar la magra realidad social y política del continente.

Leopoldo Zea (1949), en uno de sus primeros libros, Dos etapas del pensamiento en Hispanoamérica, planteó una tesis que tendrá mucha discusión posterior: la del inicio de un pensamiento propio que señale la diferencia latinoamericana. Uno de los capítulos del libro se titula justamente, "Emancipación política y emancipación mental”, en el que repasa (adhiriendo) los postulados emancipatorios de los románticos, pero rechazando su sentido antipopular. Aquí, la independencia es (todavía) cultural y política, se asocia con la respuesta a la pregunta por el “¿Qué somos?”, y la búsqueda de una identidad propia desde la cual se podrá levantar proyectos políticos y filosóficos que den respuesta efectiva a los propios problemas latinoamericanos, es decir, que permitan alcanzar la "Emancipación mental de América"; y dejar de ser una "colonia mental del pasado" (Zea 1972).

Zea recupera a los emancipadores:

La hora de los guerreros había pasado. Las armas no bastaron para alcanzar la auténtica emancipación de América. Esta emancipación tendría que ser alcanzada por otros medios: concretamente el de la educación. Un nuevo tipo de emancipador aparece en la América hispana: una combinación de guerrero y educador, porque no sólo expone ideas sino que también lucha por ellas. Allí tenemos al argentino Sarmiento vistiendo la casaca militar al mismo tiempo que prepara los elementos que le permitirán reeducar a su patria. Allí el chileno Bilbao sufriendo, al igual que otros que se le asemejan, destierros y persecuciones. Todos ellos sufren mil calamidades pero se mantienen firmes en sus ideas en lucha abierta contra los representantes de ese pasado colonial que se niega a dejar su sitio a una América libre y progresista (Zea 1972). 
Más adelante escribe:

Los emancipadores mentales de la América sostienen, en apoyo de sus ideas, una nueva idea de la filosofía. Ya no creen, como los ilustrados, en el hombre como idea universal. El hombre es algo concreto, algo que se hace y perfila dentro de una realidad determinada. Conocer esta realidad era así una de las más urgentes tareas, pues de ella dependía la educación de ese hombre al que se trataba de independizar por el más seguro de los medios, el de su emancipación mental. En adelante no se seguirían doctrinas filosóficas determinadas por el hecho de que se encontrasen de moda. Y lo mismo se diría de otras formas de cultura. De la cultura europea sólo se tomarían las ideas que concordasen con la realidad americana (Zea 1972) ${ }^{13}$.

La "Emancipación mental" de Barreda, para Zea, dará origen al primer pensamiento propiamente latinoamericano: el positivismo.

\section{TERCERA REFLEXIÓN: DE LA INDEPENDENCIA CULTURAL A LA ECONÓMICA}

En el pensamiento del comunista chileno Luis Emilio Recabarren (18761924) y en otros miembros de la llamada Generación del Centenario (1910) implícitamente se habla de una Segunda Independencia, al insistir, una vez más, que la primera no había logrado los frutos esperados, pero ahora desde la perspectiva de las masas populares que se mantenían al margen como perdedores, lo que dio origen a la denominada "cuestión social". Dice Recabarren: “ $i(\ldots)$ miro el pasado a través de mis 34 años y no encuentro en toda mi vida una circunstancia que me convenza que he tenido patria y que he tenido libertad...! (...) ¡Celebrar la emancipación política del pueblo! Yo considero un sarcasmo esta expresión. Es quizás una burla irónica" (Recabarren 1910). Recabarren da inicio al intento de una independencia económica.

Durante la primera mitad del siglo XX serán los partidos de origen popular (socialistas, comunistas y algo los radicales), los que mantendrán el uso de una Segunda Independencia, ahora del "Imperialismo", sobre todo norteamericano, que aplasta al Nuevo Mundo, creencia que tendrá mucha aceptación y vigencia a mediados del siglo XX.

\footnotetext{
${ }^{13}$ Véase, en, http://www.ensayistas.org/filosofos/mexico/zea/bibliografia/acc/VIII.htm.
} 
Para los que vivimos los años 60 en Chile y sus intentos de cambio social, el concepto Segunda Independencia nos resulta familiar, pues formaba parte del lenguaje que dominaba el ambiente político de la época con repercusiones en la prensa, en los debates intelectuales, y en el vocabulario de los partidos políticos progresistas ${ }^{14}$.

Durante el gobierno de la Unidad Popular (1970-1973), el concepto fue usado explícitamente por el Presidente Allende, en los términos señalados: liberarse del imperialismo norteamericano, para lograr una segunda independencia, esta vez "económica", que permitiera eliminar la pobreza, la cesantía, la mala distribución de la tierra, y construir un mundo más justo, en unión con los países subdesarrollados del mundo.

En ocasiones, Salvador Allende agregó cierto antihispanismo similar al de los primeros románticos, en el sentido de reprochar la forma de actuar del conquistador en contra de los pueblos originarios, pero un antihispanismo entrelíneas, probablemente marcado por la figura de Franco, todavía en el poder, pues las diferencias con los románticos del siglo XIX son evidentes: ahora no se trata de afrancesar a Chile, sino de latinoamericanizarlo. O de tercermundizarlo.

En este contexto, se establecía que la primera independencia, la de 1810, había logrado cortar los lazos políticos con la metrópoli peninsular, lo que había sido celebrado durante los primeros 100 años como un logro formador de las ciudadanías (poco) y de las élites y del Estado (mucho). Es decir, si la expresión Segunda Independencia se venía utilizando desde el comienzo mismo de la constitución de una cultura latinoamericana independiente, fue a partir de las proclamas de la izquierda de los años sesenta que se revitalizó y popularizó como un concepto clave para comprender la historia contemporánea de América Latina, y de aceptación unánime entre las posiciones progresistas, que se diferenciaban en cómo alcanzar esa Segunda Independencia, según las posiciones más reformistas o más revolucionarias.

En la política chilena se intentó un cambio social desde tres modalidades: a través de las reformas de inspiración católica, de la izquierda legal, y una última, levantada por la izquierda revolucionaria.

1. En el primer caso, la búsqueda de la Segunda Independencia estuvo presente en los objetivos del gobierno democratacristiano de Eduardo Frei Montalva (1964-1970), que aspiraba a realizar en Chile una "Revolución en

\footnotetext{
${ }^{14}$ Incluso el conjunto de música folclórica Inti-Illimani, en el álbum Viva Chile (1973), incluyó la canción "La Segunda Independencia".
} 


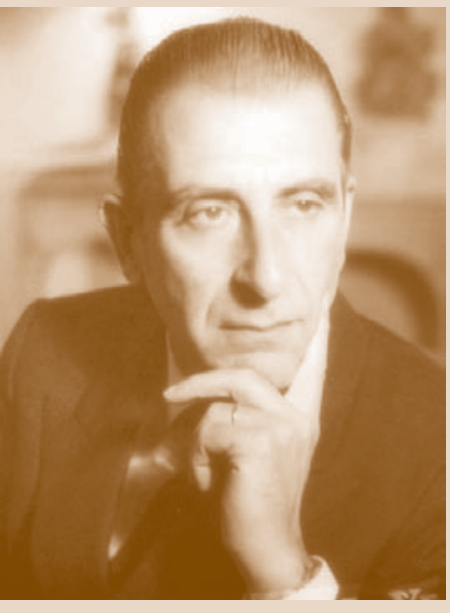

E. Frei

Libertad" (por oposición a la cubana), que permitiera modernizar la economía, aumentar la participación popular, ampliar la democracia política, internacionalizar el país, disminuir la deuda externa, y profundizar la Reforma agraria. Un amplio proyecto extendido entre las diversas capas sociales del país, para lograr definitivamente el fin del subdesarrollo y la incorporación a la modernidad.

2. Aquel intento no funcionó del todo y se transformó en lo que Tomás Moulián (1985) ha llamado un "reformismo incompleto", que precipitó la llegada al poder, en la siguiente elección presidencial, de la Unidad Popular con Salvador Allende a la cabeza, que buscaba profundizar el proyecto de Frei con un programa que permitiera realizar cambios drásticos en la sociedad chilena, pero dentro del sistema político e institucional vigente. La Segunda Independencia se alcanzaría a través de lo que se denominó la "Vía chilena al socialismo". Una izquierda legal que actuaba al interior de la "institucionalidad burguesa" para probar que sí era posible alcanzar el socialismo democrático, evitando el enfrentamiento y la crisis social (Pinedo 2002: 101-110).

En opinión de Salvador Allende, la primera independencia no había logrado la autonomía económica, lo que abría un debate que resulta central en la época, en torno a la pregunta sobre si la nueva (segunda) independencia podía alcanzarse a través del desarrollo del país por medio de medidas que permitieran expandir la economía interna, diversificar las exportaciones, controlar la inflación y equilibrar la balanza de pagos, como la única forma de superar el subdesarrollo y una pobreza indignante que alcanzaba casi a la mitad de la población.

Esta era la mirada que se ofrecía desde la CEPAL (Raúl Prebisch, Jorge Ahumada, Osvaldo Sunkel), junto a programas políticos reformistas que aceptaban parte del liberalismo económico, pero fusionado con una mayor participación del Estado. Es lo que se denominó Teoría del Desarrollo que consideraba que sólo con un programa como el descrito se podría poner fin a la sumisión de los países periféricos respecto a los centrales.

La Segunda Independencia establecía que el liberalismo económico clásico estaba agotado, pues después de 100 años de aplicación, no había logrado resolver el problema de la pobreza, tesis en la que coincidían el nacionalista-estatista Francisco A. Encina, el democratacristiano Jorge Ahumada, el radical Aníbal Pinto, y por supuesto, los líderes de la izquierda. Asimismo, consideraban que la democracia burguesa estaba igualmente agotada, pues no permitía la participación efectiva de las masas, que -se temía- podrían, defraudadas, explosionar el sistema. 
En esta otra mirada, que se quería más revolucionaria, la Segunda Independencia se lograba, sobre todo, desde un Estado cada vez más comprometido en acelerar los cambios sociales, postulando que desde la primera independencia, la influencia y control del imperialismo inglés, primero, y del estadounidense después, habían evitado el desarrollo económico y la libertad social, manteniendo a las jóvenes repúblicas latinoamericanas en la esclavitud del poder central situado en Londres y Washington. Después de ciento cincuenta años de independencia, se observaba una América Latina que giraba en un círculo vicioso basado en la producción y venta de materias primas, y golpes de Estado para someter por la fuerza a las masas desamparadas. Una América Latina que no había conocido las revoluciones burguesas, ni el capitalismo en todas sus manifestaciones y consecuencias, por lo que le correspondía a esa izquierda acelerar y realizar una primera revolución democrática, para luego pasar al socialismo pleno.

La expresión más clara de esta concepción de la historia de América Latina, como un pasar de una primera independencia política, a una segunda de carácter económico, está formulada en el Discurso de Salvador Allende desde los balcones de la Federación de Estudiantes de Chile (FECH) en la madrugada del 5 de septiembre de 1970, ante miles de ciudadanos que festejan su triunfo electoral, y su llegada, por la vía democrática, a la Presidencia de la República. Proclama Allende, con un dedo dirigido hacia el futuro, una opinión muy extendida entre la izquierda de la época:

Nunca, como ahora, sentí el calor humano; y nunca, como ahora, la canción nacional tuvo para ustedes y para mí tanto y tan profundo significado. En nuestro discurso lo dijimos: somos los herederos legítimos de los padres de la patria, y juntos haremos la segunda independencia: la independencia económica de Chile (Allende 1970a).

En estas palabras está planteada la continuidad (ideológica) entre aquellos que hicieron la primera independencia política (padres de la patria), y los nuevos líderes que conseguirían la segunda, la económica, siguiendo los planteamientos de Marx, para quien la independencia económica es la base de todas las demás libertades.

Allende habla de los "pueblos que luchan por su independencia económica y por dignificar la vida del hombre en los distintos continentes", lo que significaba construir un programa que permitiera alcanzar la "Democracia Popular" en política y el "Socialismo" en economía. Pero, socialismo no sólo en tanto que igualdad y justicia, sino también desarrollo, autonomía económica, acceso al consumo. En fin, poner fin a la pobreza y a la dependencia internacional.

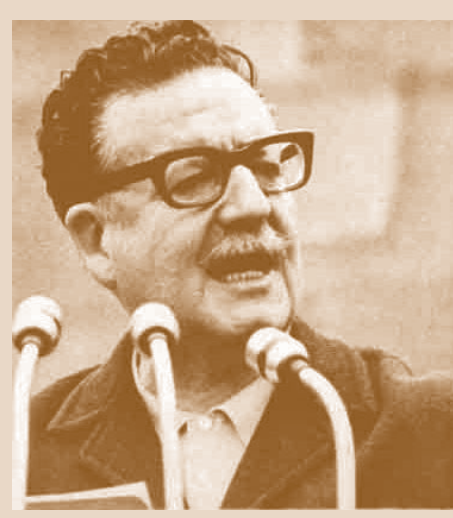

S. Allende 
Para lograr esta Segunda Independencia, el gobierno de Allende proponía:

- Legitimar la cultura popular a través de una mayor participación social, incorporando, por primera vez, ministros obreros al gobierno y estableciendo alianzas con los países del Tercer Mundo, que permitieran a Chile superar el proyecto burgués.

- Nacionalizar áreas claves de la economía, entre las cuales la del cobre, a manos del Estado, fue una de las más importantes.

- Aumentar la reforma agraria para poner fin al latifundio y resolver el problema de los "Hacendados ausentes" que mantenían enormes cantidades de tierras mal trabajadas; por lo que, un país que se consideraba eminentemente agrícola debía importar alimentos por un valor de U\$ 150 millones de la época, al año.

- Resolver los graves problemas en educación y salud.

- Redistribuir el ingreso: en 1968 el ingreso medio de los hogares más ricos era 23 veces superior al de los más pobres.

- Por último, crear una política exterior independiente que permitiera fortalecer la OEA (Organización de Estados Americanos), y respetar la autodeterminación de los pueblos: Salvador Allende fue el primer Presidente de América Latina que estableció relaciones diplomáticas con Cuba, contraviniendo las indicaciones norteamericanas.

Meses más tarde, en el discurso pronunciado por Allende en la Plaza de la Constitución de Santiago, el 21 de diciembre de 1970, al nacionalizar el cobre, insiste en la misma mirada:

Deseo ahora referirme al cobre. Y quiero que cada hombre y cada mujer que me escucha, comprenda la importancia del acto del cual vamos a firmar el proyecto destinado a modificar la Constitución Política, para que Chile pueda ser dueño de su riqueza fundamental, para que podamos nacionalizar sin apellidos, definitivamente, el cobre; para que el cobre sea para los chilenos (...) Pero el pueblo de Chile y el Gobierno Popular que presido, han medido claramente la responsabilidad de la medida que es indispensable tomar para fortalecer la economía de Chile, para romper su dependencia económica, para completar la esperanza y el anhelo de los que nos dieron la libertad política, para conquistar nuestra segunda independencia, la independencia económica de nuestra patria (Allende 1970b).

En el mismo sentido, Felipe Herrera, creador del Banco Interamericano de Desarrollo y otras instancias en las que promovió la integración latinoa- 
mericana de la manera más activa, postula que la Independencia de América Latina de comienzos del siglo XIX es un proceso terminado, pero inconcluso al que le falta una segunda etapa, que es la integración de los países americanos para poder enfrentar la nueva realidad mundial, cada vez más integrada en grandes bloques. Es un tema fundamental entre los intelectuales y políticos de izquierda en los años 60: la Segunda Independencia, cómo resolver los conflictos económicos y lograr la integración de los países de América (Herrera 1967 y 1964).

Junto con Felipe Herrera, encontramos una generación de intelectuales, constituida por los historiadores Julio César Jobet, Hernán Ramírez Necochea, Hernán San Martín; políticos como Salvador Allende, Eduardo Frei Montalva, y economistas como Jorge Ahumada, Aníbal Pinto, y los brasileños avecindados en Chile, Celso Furtado, Fernando Henrique Cardoso; sociólogos, Eduardo Hamuy, Hernán Godoy, que por primera vez plantearon, desde las ciencias sociales, la necesidad de superar los límites del Estado Nación y pensar a América Latina integrada, y de ese modo independiente, de los grandes poderes centrales.

Entre los economistas brasileros residentes en Chile, la teoría de la dependencia es el intento de romper el sometimiento de América Latina de los centros económicos mundiales, para alcanzar una nueva independencia, esta vez económica (Furtado 1969: 204).

3. Por último, la izquierda revolucionaria, que postulaba que América Latina había vivido suficiente tiempo de capitalismo, el que había llegado con el primer conquistador que puso el pie en el continente, y era el momento de dar el paso definitivo al socialismo. Un continente dominado por oligarquías explotadoras, pero a su vez sometidas y dependientes de los centros mundiales; oligarquías que giraban en un círculo vicioso en el que a lo más se podría, según André Gunder Frank (1966 y 1976), perpetuar el subdesarrollo y la dependencia, y constituir débiles burguesías subdesarrolladas, en comparación con las del mundo moderno.

\section{CUARTA REFLEXIÓN: LA SEGUNDA INDEPENDENCIA ALCANZADA}

El intento de conquistar una Segunda Independencia por parte de Salvador Allende y la Unidad Popular no logró implementarse y una serie de situaciones internas y externas hicieron que ese proceso fuera violentamente interrumpido por el golpe militar de 1973, imponiéndose en la sociedad chi- 
IIBRO

BLANCO

DEL CAMBIO DE GOBIERNO EN CHIL:

Irdeistpticmbreideit973

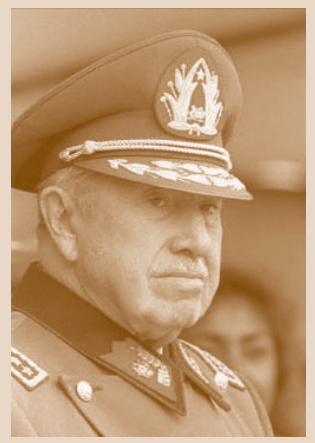

A. Pinochet lena, a partir de entonces, un proyecto de modernización neoliberal, opuesta en sus principios básicos al proyecto anterior. Sin embargo, el concepto de Segunda Independencia no fue del todo olvidado, pues los militares también recurrieron a ella para expresarla como la liberación del "comunismo internacional" y el sustento de la dictadura (Anónimo 1973).

En este contexto, el concepto de Segunda Independencia adquiría una nueva connotación semántica para justificar las circunstancias históricas marcadas por el atropello sistemático a los derechos humanos, desde el terrorismo de Estado. Más aún, durante años el lema de la dictadura de Pinochet fueron las fechas "1810-1973", señalando el carácter adánico de la dictadura al indicar, precisamente, que entre la primera independencia (1810) y el golpe militar (1973) no había sucedido nada digno de mención ${ }^{15}$.

Históricamente hablando, si el intento por incorporar a las masas de obreros y campesinos al gobierno y a la dirección del país no resultó a pesar de los esfuerzos (y la vida) de Salvador Allende, en cambio el propósito de volver atrás y reincorporar a la burguesía en el control político por medio de una revolución neoliberal, sí tuvo éxito, con el costo conocido de cárcel y muerte. Desde este punto de vista, la dictadura militar realizó una "revolución capitalista", cuyas consecuencias son perceptibles hasta hoy. Pero, con una gran diferencia respecto a la concepción de la izquierda, pues para ésta, la Segunda Independencia es algo siempre pendiente y por alcanzar a través de la liberación de las masas postergadas y de la modificación del modelo económico. En cambio, los militares, con una concepción simplista de la historia, consideraron la Segunda Independencia como algo alcanzado de una vez y para siempre: la eliminación del marxismo y de cualquier proyecto alternativo, por la acción de un grupo armado que asalta el poder e impone por la fuerza un sistema económico y social.

\section{QUINTA REFLEXIÓN: LA SEGUNDA INDEPENDENCIA EN EL CHILE DE HOY}

En el Chile actual el concepto Segunda Independencia es escasamente utilizado por los intelectuales, y aparece como un relicto de la sensibilidad de los 60 ; aunque puede estar implícito en el proyecto de los gobiernos democráticos de los últimos años.

\footnotetext{
${ }^{15}$ De un punto de vista conservador, el concepto Segunda Independencia se había asociado al elogio a Diego Portales y la defensa de la soberanía territorial de Chile en relación a sus vecinos. Véase, por ejemplo, Barros Jarpa (1956).
} 
Si la historia tiene algún sentido y este sentido es dialéctico, la época actual, la Concertación de Partidos por la Democracia, en el gobierno desde 1990, ha estado marcada por cierta síntesis entre el proyecto socialista y liberal.

Por una parte, se recoge el sentido social y comunitario de la izquierda, pero sin perder de vista la modernización de la sociedad y el desarrollo económico y técnico (comprobado en cifras objetivas), así como la regulación del Estado y la entrega de áreas importantes de la economía a los privados evitando los discursos retóricos o las culpabilizaciones fáciles.

Hoy se busca el mejoramiento de los servicios y un riguroso control en el uso de los recursos del Estado, una práctica en que la eficiencia y la transparencia son fundamentales.

Es posible señalar que los esfuerzos de la sociedad chilena de los últimos veinte años han estado dirigidos a lograr una "independencia", pero no sólo verbal sino sostenida en cifras: crecimiento económico, disminución de los niveles de pobreza, funcionamiento de las instituciones republicanas, análisis, seguimiento y mejora de los sistemas educacionales y de salud, entre otros.

Una independencia que se juega con el conjunto de los países del mundo y no sólo con aquéllos peor evaluados, en una nueva visión del planeta que considera la situación de China como un exitoso capitalismo de Estado, o de los esfuerzos de Vietnam y la India por alcanzar el desarrollo económico desde la innovación tecnológica, para no hablar de Corea, Finlandia, los países de Oceanía y su reconocida transparencia política y calidad de vida.

Es decir, se trata de una independencia respecto de las propias malas prácticas de hacer política y economía, pero también en comparación a los niveles de desarrollo de los países mejor evaluados.

En este contexto, el concepto de Segunda Independencia, como una modificación radical de los parámetros económicos y sociales, ha perdido vigencia política e intelectual. Los pensadores actuales están más preocupados de cómo afecta la creciente modernización del país en los comportamientos identitarios, y aunque muchos desconfían de la modernización (como de la modernidad), no parecen tampoco reconocerse en una identidad nacional fracturada, por efectos de la larga dictadura militar, y cuya cicatrización pudiera resolverse por medio de una revolución social.

Por otro lado, el movimiento obrero y campesino parecen estar cada día más integrados a la sociedad de consumo, y sus demandas apuntan a mejoras gremiales más que a modificar el sistema vigente. Lo mismo para las minorías sexuales que se expresan cada vez con mayor libertad. En cambio, 


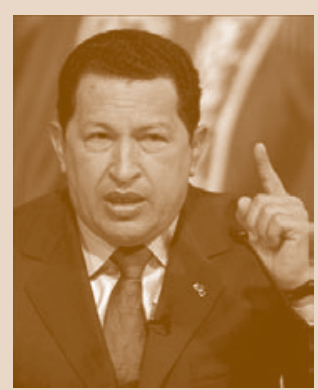

H. Chávez

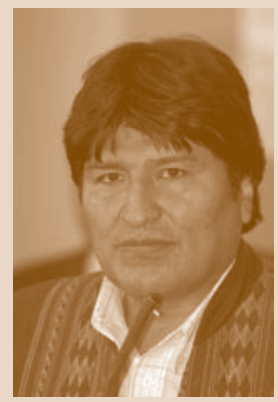

E. Morales

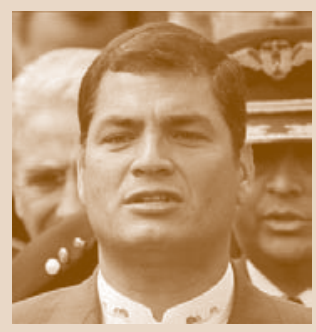

R. Correa

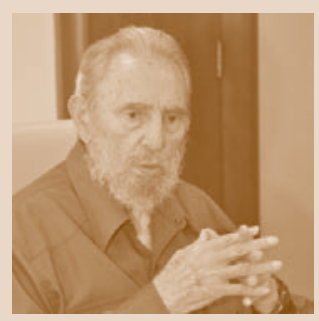

F. Castro un nuevo actor social, los indígenas mapuches, son quienes mayormente han discutido el modelo, pero con reivindicaciones puntuales, aunque tampoco parece haber en ellos un propósito fundacional.

En este sentido, el discurso intelectual chileno de los últimos años se ha diferenciado de la izquierda latinoamericana (considerada por algunos como retórica) encarnada, con sus diferencias, en los gobiernos de Hugo Chávez, Evo Morales, Rafael Correa y Fidel Castro, con los cuales se busca establecer alianzas con miradas más pragmáticas que ideológicas; y con excepción de la izquierda extraparlamentaria (Partido Comunista) muy pocos hablan hoy de la "refundación de América Latina". Vivimos una época con una política más práctica y menos creyente en un discurso utópico; lo que supone el fin de un intelectual que se presenta con la capacidad de construir el futuro, provocar el cambio social, e inaugurar una nueva sociedad (Pinedo 2000: 189-232).

En los pensadores chilenos posteriores a la dictadura militar, o durante ella, no veo alusiones directas al tema de la Segunda Independencia, al menos no de la manera en que se presentaba entre los liberales del siglo XIX y los socialistas de los 60 . No se habla, por ejemplo, de tomar distancia del Fondo Monetario Internacional y, por el contrario, se acogen sus sugerencias en cuestiones de financiamiento de la educación universitaria, y otras. Tampoco se cuestiona a las empresas españolas, sino que se celebran sus inversiones, sin considerar que esto suponga una segunda conquista. Incluso, en estos años de "transición a la democracia", que se inician en 1990, España (tradicionalmente asociada con atraso y despotismo), ha ganado en imagen como un país que nos ayudó contra la dictadura y que ha logrado constituirse en un miembro activo de la Comunidad Europea: el país que probablemente ha tenido la mejor transición de una sociedad tradicional a la actual, moderna y desarrollada.

Y si el balance económico es analizado desde el punto de vista de la cesantía, la inflación, la corrupción y el crecimiento económico, estos males son vistos como un problema, en buena medida, de administración interna. Es decir, hemos pasado de la politización a la economización, en contra, incluso, de aquellos que ayer defendían la independencia económica y que hoy reclaman que no todo es dinero en la vida humana, reencarnando una nueva venganza de Hegel contra Marx.

Recientemente, un grupo de intelectuales pertenecientes al llamado "pensamiento alternativo" ha publicado el libro América Latina hacia su segunda independencia. Memoria y autoafirmación (Biagini y Roig 2007), en el que se 
retoma el concepto analizado: ¿Cuáles son las esperanzas en esta Segunda Independencia? ¿De qué deberíamos independizarnos hoy?

En primer lugar, alcanzar "las causas inconclusas" de la primera independencia, que consideran "trunca o incompleta", en cuestiones como la integración continental, una mayor igualdad social y una identidad común que recupere la memoria colectiva continental.

En esta mirada, la elección de Rafael Correa en Ecuador, junto a la presencia de Lula en Brasil, Bachelet en Chile, Evo Morales en Bolivia y, por supuesto, de Hugo Chávez en Venezuela, es vista como el inicio de la Segunda Independencia, y que las naciones latinoamericanas "dispongan de la capacidad para actuar por cuenta propia" (Biagini y Roig 2007: 16) ${ }^{16}$; pues al asociar la Primera Independencia a la liberación del dominio colonial español, la Segunda actualiza ese colonialismo representado ahora por las empresas transnacionales, los EE.UU., el Foro Económico Mundial, el neoliberalismo y la globalización, frente a los cuales el prestigioso pensador Arturo A. Roig ha planteado la "necesidad de una segunda independencia", y las armas para lograrla son la teoría de la dependencia (años 60), y la Teología de la Liberación (años 70). Lo que Roig ha definido como un "rearme categorial” (Roig 2007: 32); es decir una independencia, también, del pensamiento postmoderno, débil y sin sujeto, que no haría sino confundir a los latinoamericanos, recuperando, en cambio, un pensamiento fuerte, que utilice sin temor las categorías que denuncian la injusticia y proponen la emancipación.

Así, de manera similar a los emancipadores mentales del siglo XIX, se trata también de una independencia del lenguaje y del pensamiento, para alcanzar un modo propio de expresión, que no imite al mundo desarrollado.

De este modo, si la primera emancipación fue mayoritariamente extranjerizante, la de hoy toma el papel de su contrario, al oponerse a lo venido desde afuera en cultura, política y economía: “ ¿Y cuál es la actual situación de la casi mayoría absoluta de los estados latinoamericanos, sometidos a las políticas del neoliberalismo dentro de los marcos de la llamada 'globalización'? En el número de octubre del año 2002, en la edición francesa de Le Monde Diplomatique, en un artículo titulado "Vasallaje", el articulista decía: 'Un imperio no tiene aliados, no tiene más que vasallos"' (Roig 2007: 30).

\footnotetext{
cia”.

${ }^{16}$ A su vez, esos mismos mandatarios identifican su gestión como una "Segunda independen-
}

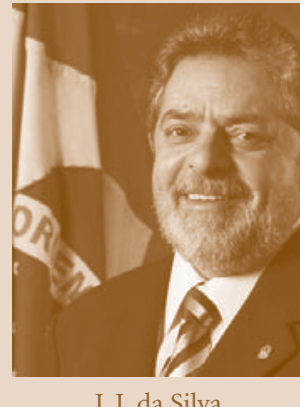

J. I. da Silva

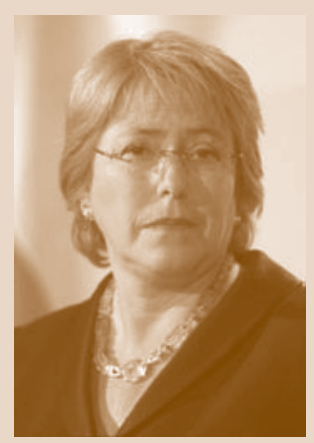

M. Bachelet 
Son tantas las esperanzas en esta nueva Segunda Independencia, que se podría temer que se repitan las frustraciones de la primera; pues en muchos intelectuales se observa un excesivo interés por resolver los problemas de la política y la economía, desde la filosofía y la cultura, lo que redunda en cierta confusión entre utopía y realidad, o al drama de partir, adánicamente, y una vez más, desde el inicio, con lo cual contribuyen a participar en uno de los deportes favoritos de América Latina: provocar la crisis del Estado; de un Estado que, la mayor parte del tiempo, está en crisis.

\section{UNA PROPUESTA EN LA MIRA DEL BICENTENARIO}

El desarrollo económico, político y cultural de América Latina se debe seguir consolidando, con programas que beneficien a las mayorías, y con políticos que apliquen inteligencia y voluntad para alcanzar una, cada vez mayor, integración regional.

En este contexto, independencia significa autonomía para tomar las propias decisiones, pero también para establecer alianzas que aseguren el bienestar colectivo. Independencia significa una América cada vez más lúcida y consciente de su memoria y orgullosa de sus logros. Independencia es no olvidar lo que hemos aprendido en los oscuros años de la muerte: a desconfiar del triunfalismo fácil y, sobre todo, de las desgracias que provoca ignorar la realidad. Hemos aprendido de la necesidad de una "política limpia" (Roig) y eficiente, pero también que un orden más equitativo en lo social, sólo se logra con crecimiento económico, y hemos aprendido del valor de la democracia, sin apellidos.

Para muchos países de América Latina la década del ' 80 fue mala y la del '90, peor. Y sin embargo, no podemos renunciar al optimismo de una América que cada día produce nuevas síntesis de tradición popular y cultura universal, producto de uno de los ejes claves de nuestro mundo: el mestizaje y la interculturalidad.

Ser nosotros mismos aportando a la humanidad, es una buena manera de ser independientes, sin olvidar el desarrollo económico, que se alcanza con más investigación científica y tecnológica, mayor capital humano, es decir, más educación.

La tríada: Primera independencia, Centenario, Segunda Independencia hace que muchos pensadores mantengan, desde una u otra posición, ciertos temas comunes que parecían incorregibles desde el comienzo y por tanto, la necesidad de eliminar la pobreza, extender la justicia social, y superar un 
estado de crisis social, y de un Estado en crisis, en que veían al país. Tal vez, el Bicentenario sea una buena fecha para dejar, definitivamente, esas lacras sociales en el pasado.

\section{REFERENCIAS}

Alberdi, Juan Bautista. 1980. Bases y puntos de partida para la organización política de la República Argentina (1852). Caracas: Biblioteca Ayacucho.

Allende, Salvador. 1970a. Discurso desde los balcones de la Federación de Estudiantes de Chile (FECH) en la madrugada del 5 de septiembre. Disponible en: http://www.archivochile.com/S_Allende_UP/doc_de_sallende/SAde0051. pdf [Consulta: 15.08.10].

Allende, Salvador. 1970b. Discurso pronunciado en la Plaza de la Constitución de Santiago, el 21 de diciembre. Disponible en: En: http://www.archivo chile.com/S_Allende_UP/doc_de_sallende/SAde0048.pdf [Consulta: 15.08.10].

Anónimo. 1973. Libro blanco del cambio de gobierno en Chile. 11 de septiembre de 1973. Santiago: Editorial Lord Cochrane.

Arendt, Hanna. 1988. Sobre la revolución. Madrid: Alianza.

Barreda, Gabino. 1867. “Oración cívica”, en Antología del ensayo. Disponible en http://www.ensayistas.org/antologia/XIXA/barreda/ [Consulta: 22.04.2010].

Barros Jarpa, Ernesto. 1956. La "Segunda Independencia”. Santiago: Zig-Zag.

Biagini, Hugo E. y Roig, Arturo A. (compiladores). 2007. América Latina hacia su segunda independencia. Memoria y autoafirmación. Buenos Aires: Aguilar, Altea, Taurus, Alfaguara.

Bilbao, Francisco. 1844. La sociabilidad chilena, en El Crepúsculo. Santiago: [s.n.], 2 v., tomo 2, N², pp. 57-90.

Bilbao, Francisco. 1993. "Iniciativa de la América. Idea de un congreso federal de las repúblicas”, en Leopoldo Zea (Compilador), Fuentes de la cultura latinoamericana. México: FCE, tomo I, pp. 53-66.

Bolívar, Simón. 1979. “Carta de Jamaica. Kingston, 6 de septiembre de 1815”, en Simón Bolívar. Doctrina del libertador. Caracas: Biblioteca Ayacucho.

Candia Baeza, Cristián. s./f. "Filosofía, identidad y pensamiento político en Latinoamérica”, Polis. Revista Académica Universidad Bolivariana, $\mathrm{N}^{\circ} 18$. Santiago de Chile [en línea], http://www.revistapolis.cl/18/filo.htm [Consulta: 14.05.2010].

Echeverría, Esteban. 1873. Obras completas. Buenos Aires: Imprenta y Librería de Mayo.

Frank, André Gunder. 1966. Desarrollo en el subdesarrollo. México: MRP.

Frank, André Gunder. 1976. Capitalismo y subdesarrollo en América Latina. México: Siglo XXI. 
Furtado, Celso. 1969. La economía latinoamericana desde la Conquista Ibérica hasta la Revolución cubana. Santiago de Chile: Universitaria.

Gutiérrez, Juan María. 1929. "Noticias biográficas sobre don Esteban Echeverría", en Letras Argentinas, Colección Grandes escritores argentinos. Buenos Aires: El Ateneo, t. XXVI, p. 122.

Herrera, Felipe. 1964. América Latina integrada. Buenos Aires: Losada.

Herrera, Felipe. 1967. Nacionalismo latinoamericano. Santiago: Universitaria.

Jalif, Clara. 2003. Francisco Bilbao y la experiencia libertaria en América. La propuesta de una filosofía americana. Mendoza, Argentina: Editorial de la Universidad Nacional de Cuyo (Ediunc).

Kaempfer, Álvaro. 2006. "Lastarria, Bello y Sarmiento en 1844: Genocidio, historiografía y Proyecto Nacional", en Revista de Crítica Literaria Latinoamericana, año XXXII, N ${ }^{\text {os }}$ 63-64. Lima-Hanover, $1^{\circ}$ y $2^{\circ}$ semestres, pp. 9-24.

Larraín, Jorge. 2005. ¿América Latina moderna? Santiago: Lom.

Lastarria, José Victorino. 1993. La América (1844), en Leopoldo Zea (compilador), Fuentes de la cultura latinoamericana. México: FCE, tomo II, pp. 493511.

Loyola, Manuel; Pinedo, Javier; Roig, Arturo Andrés; Salas Astrain, Ricardo. 2005. "Reseñas del libro Francisco Bilbao y la experiencia libertaria en América. La propuesta de una filosofía americana, de Clara Jalif, Universidad Nacional de Cuyo, Ediunc, Mendoza, 2003”. Universum, Inst. de Estudios Humanísticos, Universidad de Talca, No 20, Vol. 1, pp. 245-264.

Luis Mora, José María. 1986. Revista política de las diversas administraciones que la República Mexicana ha tenido hasta 1837. México: Porrúa. Edición facsimilar en http://www.cervantesvirtual.com/FichaObra.html?Ref=2079 [Consulta: 07.06.2010].

Martí, José. 1977a. Nuestra América. Caracas: Editorial Ayacucho.

Martí, José. 1977b. "Congreso internacional de Washington” (Nueva York, 2 de noviembre 1889), en Nuestra América. Caracas: Editorial Ayacucho.

Moulián, Tomás. 1985. "Violencia, gradualismo y reformas en el desarrollo político chileno", en VV.AA, Estudios sobre el sistema de partidos en Chile. Santiago: Flacso.

Ossandón, Carlos. 1984. "Una tarea del liberalismo decimonónico: la emancipación mental”, Anuario de Filosofía Jurídica y Social, Valparaíso, № 2 .

Pinedo, Javier. 2000. “Pensar en (la) transición. Intelectuales chilenos durante el proceso de transición a la democracia. 1990-1999”, Universum, Inst. de Estudios Humanísticos, Universidad de Talca, No 15, pp. 189-232.

Pinedo, Javier. 2002. "La vía chilena al socialismo de Salvador Allende y su relación con la modernidad", Cuadernos Americanos, México, № 92, marzo-abril, pp. 101-110.

Recabarren, Luis Emilio. 1910. Ricos y pobres en un siglo de vida republicana. Santiago: Imprenta New York.

Roig, Arturo A. 1981. "Acerca de la significación del 'nosotros", en Teoría y crítica del pensamiento latinoamericano. México: FCE. 
Roig, Arturo A. 2007. "Necesidad de una segunda independencia", en Biagini, Hugo E. y Roig, Arturo A. (compiladores), América Latina hacia su segunda independencia. Memoria y autoafirmación. Buenos Aires: Aguilar, Altea, Taurus, Alfaguara.

Romero, José Luis y Romero, Alberto. 1977. Prólogo y selección, El pensamiento de la emancipación (1790-1825). Caracas: Ayacucho.

Sarmiento, Domingo Faustino. 1850. Argirópolis. Santiago de Chile.

Sarmiento, Domingo Faustino. 1883. Conflictos y armonías de las razas en América. Buenos Aires: Imprenta de Túñez.

Subercaseaux, Bernardo. 1981. Lastarria, ideología y literatura. Santiago: Editorial Aconcagua.

Volek, Emil. 2007. "José Martí, Nuestra (Macondo) América“, Universum, Inst. de Estudios Humanísticos, Universidad de Talca, No 22, Vol. 1.

Zea, Leopoldo. 1949. Dos etapas del pensamiento en Hispanoamérica. México: El Colegio de México.

Zea, Leopoldo. [1953] 1972. América como conciencia. México: UNAM (1ª edición: México: Cuadernos Americanos). 